\title{
PERITROCHANTERIC FRACTURES - SURGICAL MANAGEMENT BY PF - LCP
}

Kiran Kalaiah¹, H. P. Shobha², Giridhar Kumar², Vimalan G ${ }^{4}$

\section{HOW TO CITE THIS ARTICLE:}

Kiran Kalaiah, H. P. Shobha, Giridhar Kumar, Vimalan G. "Peritrochanteric Fractures - Surgical Management by PF - LCP". Journal of Evolution of Medical and Dental Sciences 2014; Vol. 3, Issue 29, July 21; Page: 7962-7973, DOI: $10.14260 /$ jemds/2014/2997

ABSTRACT: Background and objectives: - Due to increasing life span and sedentary habits of elderly people fractures around hip are common. Among these, peritrochanteric fractures are commonest and they need immediate and stable reconstruction to mobilize the affected patients. METHODS: We studied 20 cases of peritrochanteric fractures treated by PF-LCP at KR hospital, MMCRI from Sep 2013- May 2014. They included 14 male and 6 female patients of age group from 28 yrs. to 75 yrs. the cause of injury was trivial in $80 \%$, RTA in $20 \%$ of cases. Follow up was done for 6-8 months and assessed using Boyd and Griffin's classification and Harris hip score. RESULTS: Among the selected cases we evaluated both clinically and radiologically at the intervals of $6^{\text {th }}, 12^{\text {th }}$, and 6 months we found that the final outcome was better than the cases treated with other type of implants and treated conservatively. The union rate was 40\% (8/20) and 85\% (17/20) at the $12^{\text {th }}$ week and 6 months follow up respectively. We had 1 case of complication as cut-out of screws from proximal fragment. CONCLUSION: The peritrochanteric fractures when treated with PF-LCP resulted in stable reconstruction of fracture and maintenance of anatomical reduction and bio-mechanical axis. Because of its strong angular fixation by the top three screws PF-LCP is advantageous in all types of bone density.

KEYWORDS: Peritrochanteric fractures, PF-LCP, Boyd and Griffin, angular fixation.

INTRODUCTION: Over the past decades Peritrochanteric fractures are becoming common among adults and elderly people. In PERITROCHANTERIC FRACTURES major weight bearing joint i.e. hip is involved, hence it needs stable construct and anatomical reduction to maintain a better post-op outcome. The treatment with PF-LCP is superior due to its anatomic plate profile and flexibility to include diaphyseal fractures of femur.

Due to combination of conventional and locking plate fixation, it offers 3D fixation mechanical advantages even in the unstable fractures in osteoporotic bone. The complication rate in unstable fractures when treated by DHS or DCS has shown to be as high as $3-15 \%^{1,2}$ and also these implants cannot prevent secondary limb shortening after weight bearing due to lateralization of proximal fragments gliding along the screw. $3,4,5$

The PF-LCP is innovative and viable option with features of anatomical plate profile, plate length spanning over diaphysis in segmental fracture, by use of locking screws providing the stable angular construct independent of bone density. ${ }^{6}$ In 1958, the AO ASIF formulated 4 basic principles which have become guidelines of internal fixation are well applied to PF-LCP.7

These are- anatomic reductions

Stable fixation.

Preservation of blood supply.

Early mobilization. 
The complications like primary or secondary varus collapse and hardware failure by cut-out of the femoral head screw of DHS and higher incidence of secondary implant failure with use of cephalomedullary nails are reduced with PF-LCP.8, 9, 10

MATERIALS AND METHODS: A prospective study included 20 cases with peritrochanteric fractures in the age group 28 - 82 yrs., 14 male and 6 female patients. All these patients came to KR hospital with hip injuries. Both AP and lateral view x-rays were taken and limb immobilized in the splint. The cases are recorded as per Boyd and Griffin classification and we reported cases as- type 1- 2 cases, type 2- 9 cases, type 3- 6 cases, type 4- 3 cases. Patients evaluated for fitness for surgery and posted for PF-LCP fixation.

PROCEDURE: Under C-arm guidance the fracture configuration was checked pre-operatively. Then fracture exposed through lateral approach, hemostasis obtained using electric cautery. Fracture was reduced near to anatomical position and fixed with PF-LCP. First top 3 screws were put and then distally conventional compression screws applied to get a maximum compression at fracture site, then locking done with locking screws.

Drain was put and wound closed in layers. Check x-ray was done and dressings were checked on second post-op day, active quadriceps drill started from third post-op day and drain was removed after 36 hours. Sutures removed at 12-14 days. Limb was immobilized for 6 weeks and partial weight bearing allowed after 6 weeks. Check x-rays taken at 6 and 12 weeks and 6 months intervals.
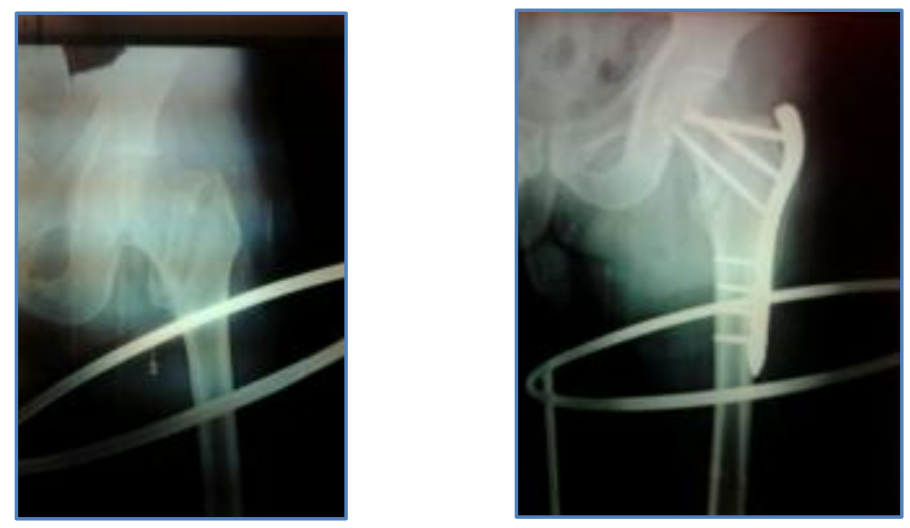

Boyd and Griffin type 1
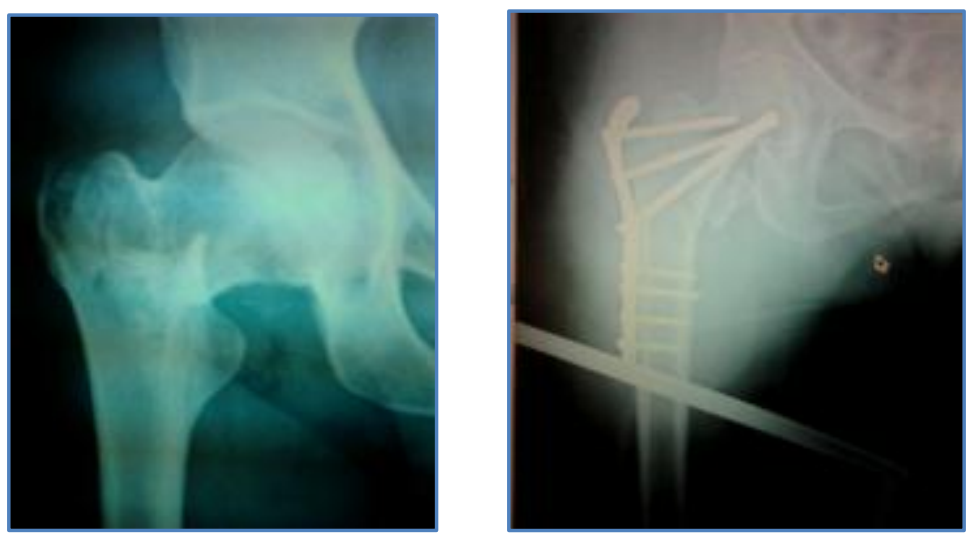

Boyd and Griffin type 2 


\section{ORIGINAL ARTICLE}
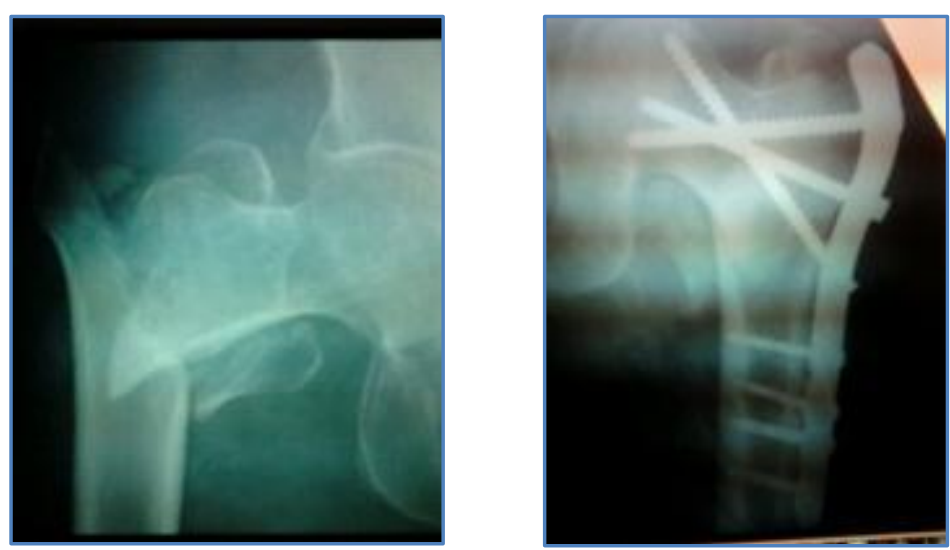

Boyd and Griffin type 3
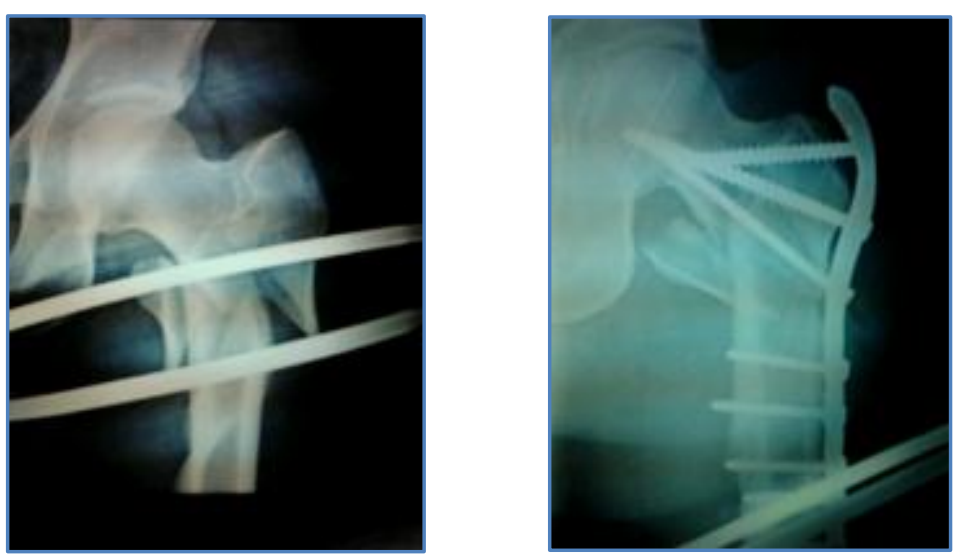

Boyd and Griffin type 4

\section{DISCUSSION:}

\section{Classification of Intertrochanteric Fractures}

\section{Boyd and Griffin classification $(1949)^{11}$ :}

Classified fractures in the peritrochanteric area of the femur into four types. Their classification, which follows, included all fractures from the extracapsular part of the neck to a point $5 \mathrm{~cm}$ distal to the lesser trochanter.

Type 1: Fractures that extend along the intertrochanteric line from the greater to the lesser trochanter. Reduction usually is simple and is maintained with little difficulty. 
Type 2: Comminuted fractures, the main fracture being along the intertrochanteric line but with multiple fractures in the cortex.. A particularly deceptive form is the fracture in which an anteroposterior linear intertrochanteric fracture occurs, as in type 1 , but with an additional fracture in the coronal plane, which can be seen on the lateral roentgenogram.

Type 3: Fractures that are basically subtrochanteric with at least one fracture passing across the proximal end of the shaft just distal to or at the lesser trochanter. These fractures are usually more difficult to reduce and result in more complications

Type 4: Fractures of the trochanteric region and the proximal shaft, with fracture in at least two planes, one of which usually is the sagittal plane and may be difficult to see on routine anteroposterior roentgenogramsIf open reduction and internal fixation is two plane fixation is required.

Type 3 and 4, most difficult types to manage account for only one third of the trochanteric fractures.

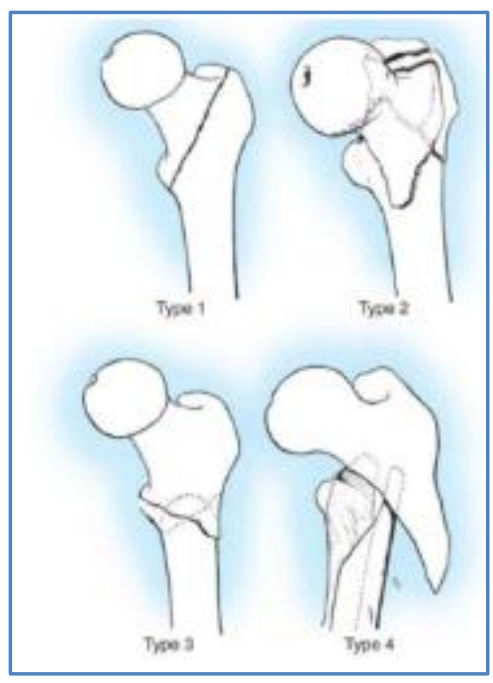




\section{Evans classification :}

Type 1: The fracture line extends upwards and outwards from the lesser trochanter.

Type 2: The fracture line is of reversed obliquity, the major fracture line extends outward and downward from the lesser trochanter and are unstable.

A widely used classification system based on the stability of the fracture pattern and the potential to convert an unstable fracture pattern to a stable reduction. Evans observed that the key to a stable reduction is restoration of posteromedial cortical continuity.

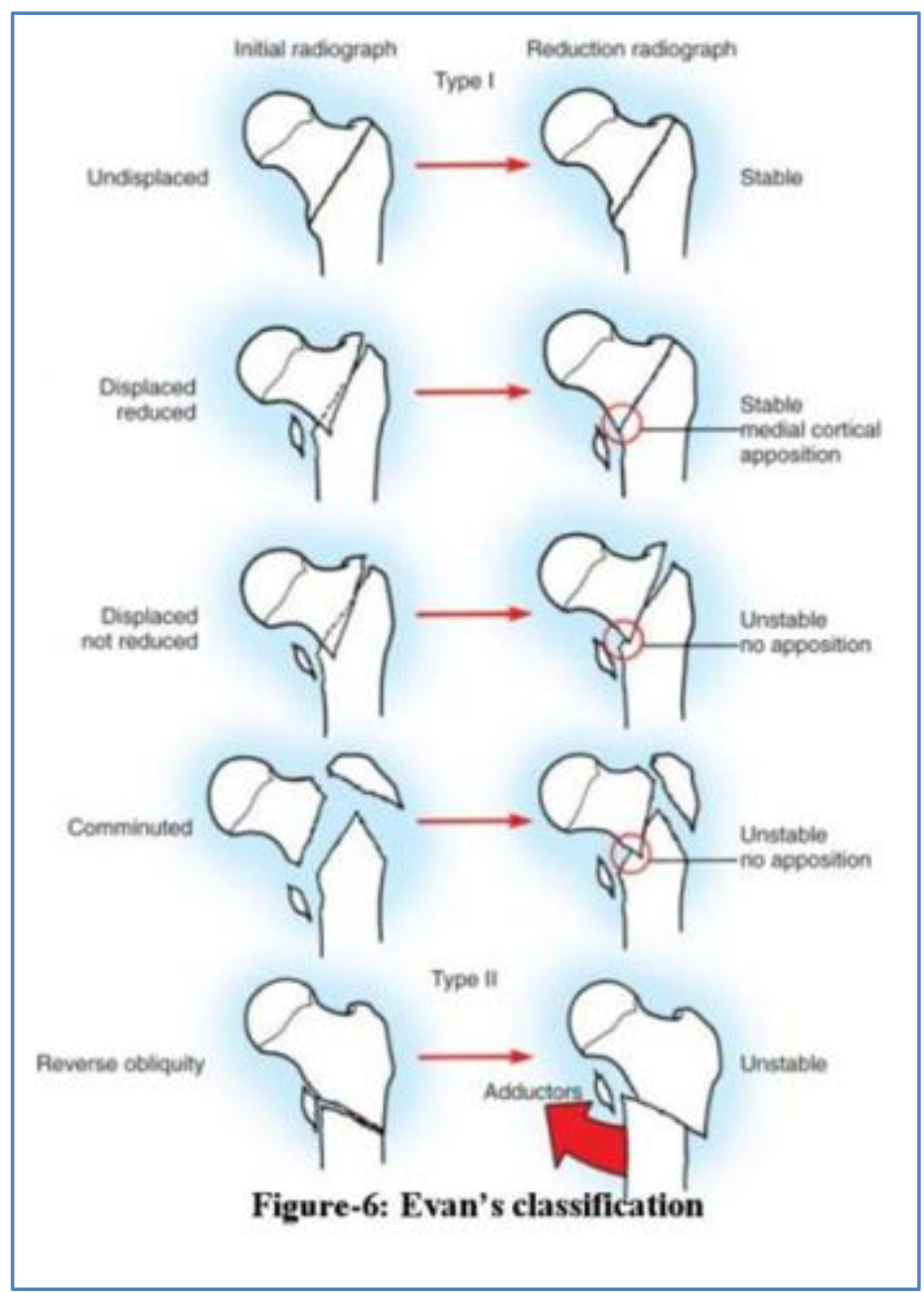




\section{5) Russell and Taylor Classification ${ }^{12}$}

Russel and Taylor devised a classification scheme based on lesser trochanteric continuity and fracture extension posteriorly on the greater trochanter involving the piriformis fossa, the major two variable influencing treatment.

Type I fractures do not extend into the piriformis fossa.

Type IA comminution and fracture lines extend from below the lesser trochanter to the femoral isthmus; any degree of comminution may be present in this area, including bicortical comminution.

Type IB have fracture line and comminution involving the area of the lesser trochanter to the isthmus.

Type II fractures extend proximally into the greater trochanter and involve the piriformis fossa, as detected on the lateral roentgenogram of the hip, which complicates closed nailing techniques.

Type IIA fracture extend from the lesser trochanter to the isthmus with extension into the piriformis fossa, as detected on lateral roentgenograms, but significant comminution or major fracture of the lesser trochanter is not present.

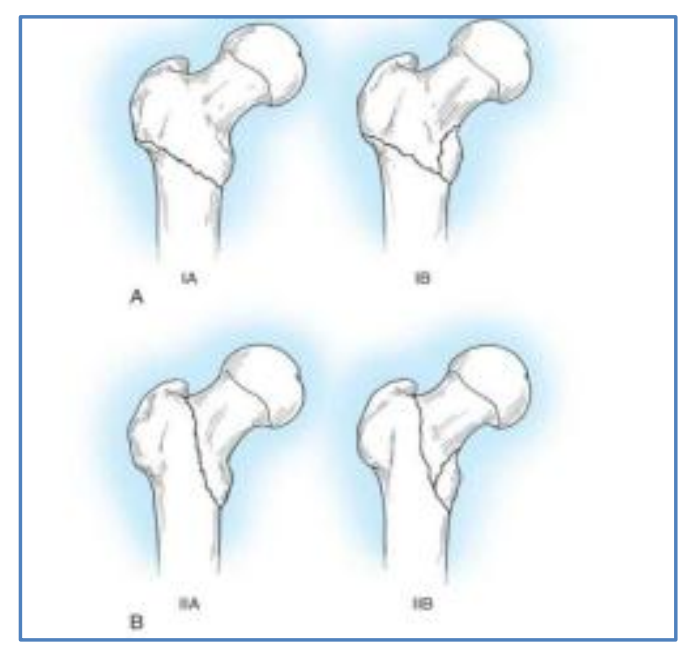




\section{ORIGINAL ARTICLE}

Type IIB the fracture extends into the piriformis fossa with significant comminution of the medial femoral cortex and loss of continuity of the lesser trochanter.

The lateral trochanteric wall is believed to be important factor in stabilizing the peritrochanteric fractures. ${ }^{13}$ When the plate is placed at the lateral side of the proximal femur acts as a stress shield and prevents the lateral migration of proximal fragments. ${ }^{14}$ Among selected cases based on Boyd and Griffin classification, we obtained a good union in type1-2 cases (100\%- 2/2), type2- 8 cases (88\%-8/9), type 3- 4 cases (80\%-4/5), type $4-3$ cases (75\%-3/4) at 6 months follow up.

We had:

Excellent results in 12 cases- $60 \%(12 / 20)$.

Good results in 5 cases- 25\% (5/20).

Fair- 2 cases- $10 \%(2 / 20)$.

Failed-1 case- $5 \%(1 / 20)$.

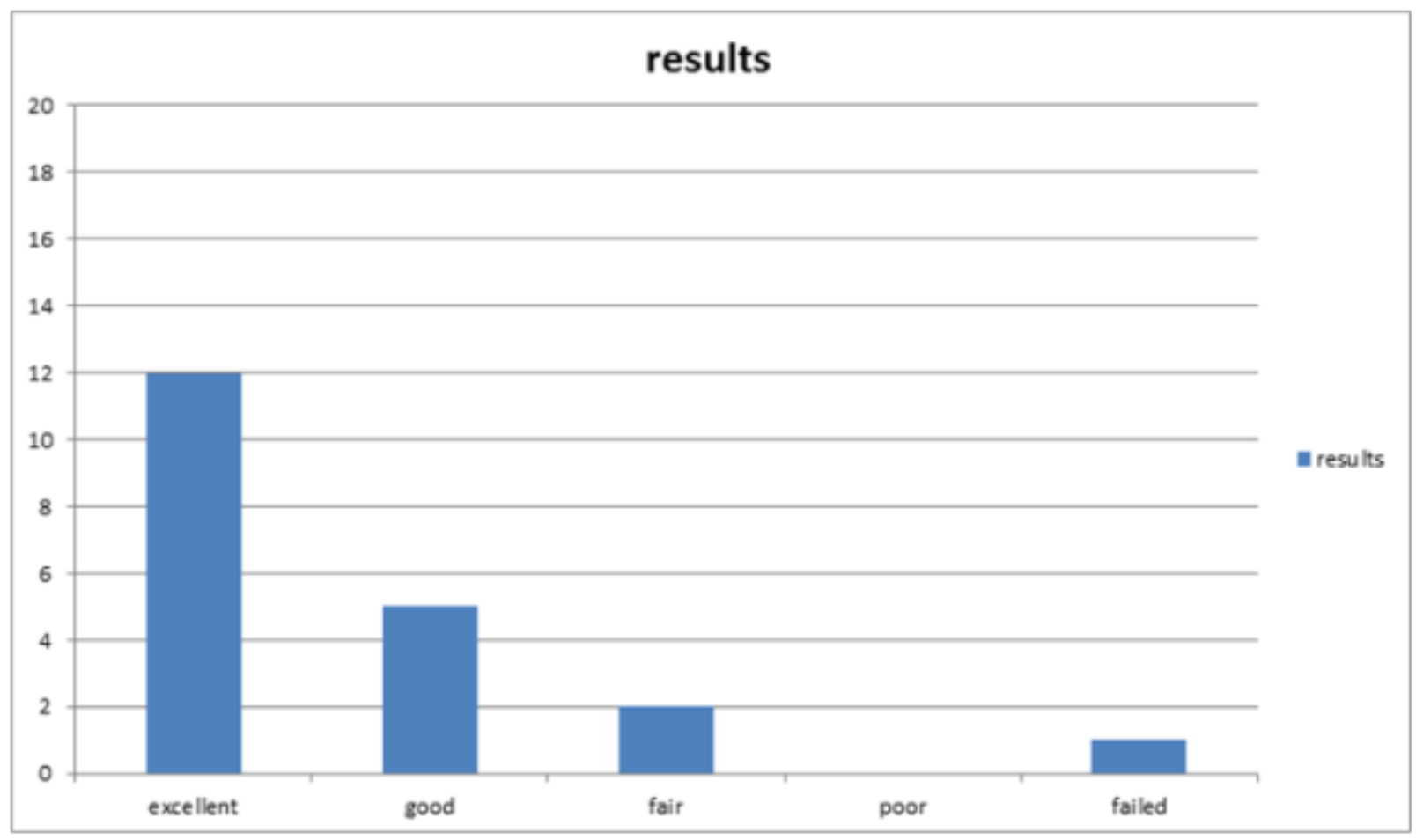

Fig. Results shown for 20 cases 
Partial loosening of the screws in 1 case and varus collapse at the fracture site and cut-out of the screws due to severe comminution and osteoporotic bone.
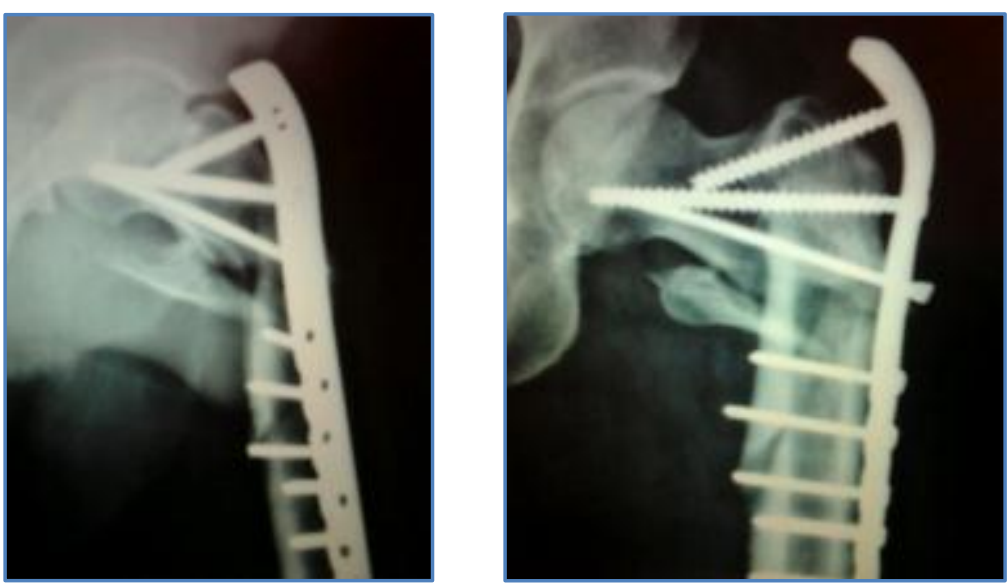

\begin{tabular}{|c|c|c|c|}
\hline Results & Score & No. of patients & Percentage of pts. \\
\hline Excellent & $90-100$ & 12 & $60 \%$ \\
\hline Good & $80-89$ & 5 & $25 \%$ \\
\hline Fair & $70-79$ & 2 & $10 \%$ \\
\hline Poor & $60-69$ & 0 & $0 \%$ \\
\hline Failed & $<60$ & 1 & $5 \%$ \\
\hline \multicolumn{4}{|c|}{ Results according to Harris hip score: } \\
\hline
\end{tabular}

CONCLUSION: For peritrochanteric fractures, now-a-days, open reduction and internal fixation has become a wide acceptance for early mobilization of a patient. As the PF-LCP placed laterally provides stress shield for the lateral fragment preventing the lateral migration of proximal fragments. Because of its stable angular reconstruct it offers stability at the fracture site and the intact lateral wall assist in fracture healing and reduce the rate of mal-union and non-union. We consider the PF-LCP is suitable for peritrochanteric fractures irrespective of bone density quality.

\section{REFERENCES:}

1. Bridle SH, Patel AD, Bircher M, Calvert PT. Fixation of intertrochanteric fractures of the femur. A randomised prospective comparison of the gamma nail and the dynamic hip screw. J Bone Joint Surg BR. 1991; 73: 330-334.

2. Nungu KS, Olerud C, Rehnberg L. Treatment of subtrochanteric fractures with the AO dynamic condylar screw. Injury. 1993; 24: 90-92.

3. Simpson AH, Varty K, Dodd CA. Sliding hip screws: modes of failure. Injury. 1989; 20:227-231.

4. Schatzker J, Mahomed N, Schiffman K, Kellam J. Dynamic condylar screw: a new device. A preliminary report. J Orthop Trauma. 1989; 3: 124-132.

5. Wolfgang GL, Bryant MH, O'Neill JP. Treatment of intertrochantric fractures of the femur using sliding screw plate fixation. Clin Orthop Relat Res. 1982; 163: 148-158.

6. Synthes LCP. Proximal Femoral Plate 4.5/5.0 Technique Guide. 


\section{ORIGINAL ARTICLE}

7. ME Muller, M Allgower, R Schneider, $\mathrm{H}$ Willenegger. AO Manual of internal fixation, $3^{\text {rd }}$ edition. Berlin: Springer- Verlag.1991.

8. Simpson AH, Varty K, Dodd CA. Sliding hip screws: modes of failure. Injury. 1989; 20: 227-231.

9. Lenich A, Mayr E, Ruter A, Mockl C, Fuchtmeier B. First results with the Trochanter Fixation Nail (TFN): a report on 120 cases. Arch Orthop Trauma Surg. 2006; 126: 706-712.

10. Utrilla AL, Reig JS, Munoz FM, Tufanisco CB. Trochanteric gamma nail and compression hip screw for trochanteric fractures: a randomised, Prospective, comparative study in 210 elderly patients with a new design of the gamma nail. J Orthop Trauma.2005; 19: 229-233.

11. Boyd HB, Griffin LL. Classification and treatment of trochanteric fractures, Arch Surg 58: 853, 1949.

12. Russell TA, Taylor JC. Subtrochanteric fractures of the femur. In Brownes BD, Jupiter JB, Levine AM, Trafton PG, eds: skeletal Trauma, ed 2, Philadelphia, 1992, WB Saunders, Schatzker J, Waddell JP: subtrochanteric fractures of the femur, Orthop Clin North Am 11: 539, 1980.

13. Gotfried Y. The lateral trochanteric wall: a key element in the reconstruction of unstable pertrochanteric hip fractures. Clin Orthop Relat Res.2004; (425): 82-6.

14. Hasenboehler EA, Agudelo JF, Morgan SJ, Smith WR, Hak DJ, Stahel PF. Treatment of complex proximal femoral fractures with the proximal femur locking compression plate. Ortopedia. 2007; 30 (8): 618-23.
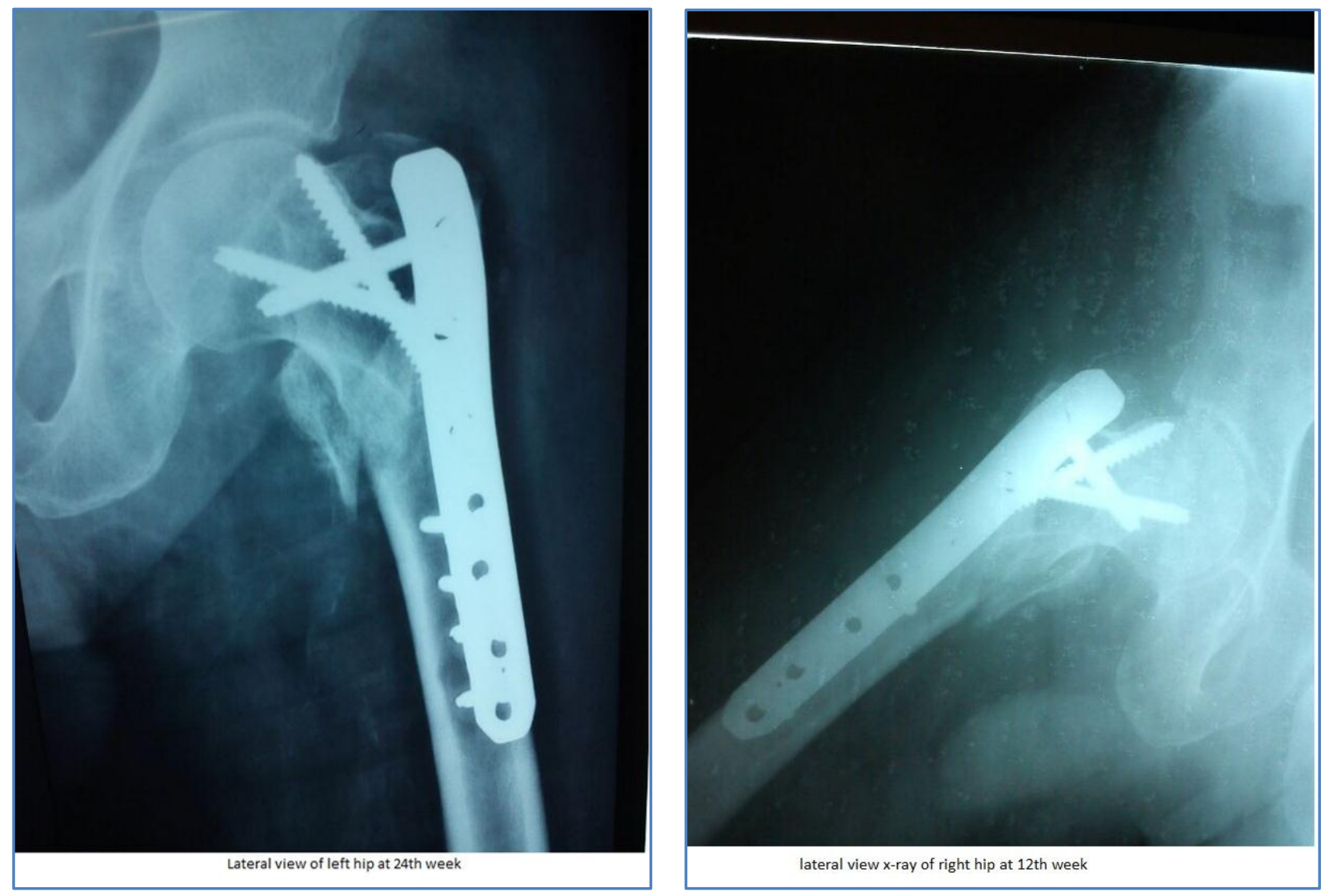


\section{ORIGINAL ARTICLE}

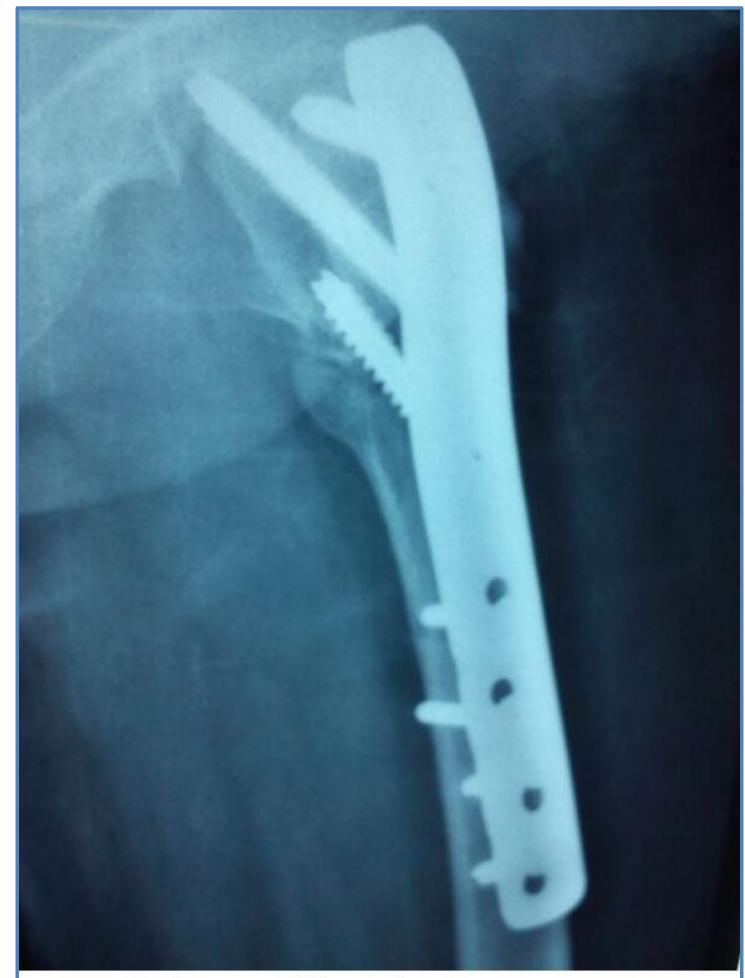

Lateral view $\mathrm{x}$-ray of left hip at 16th week

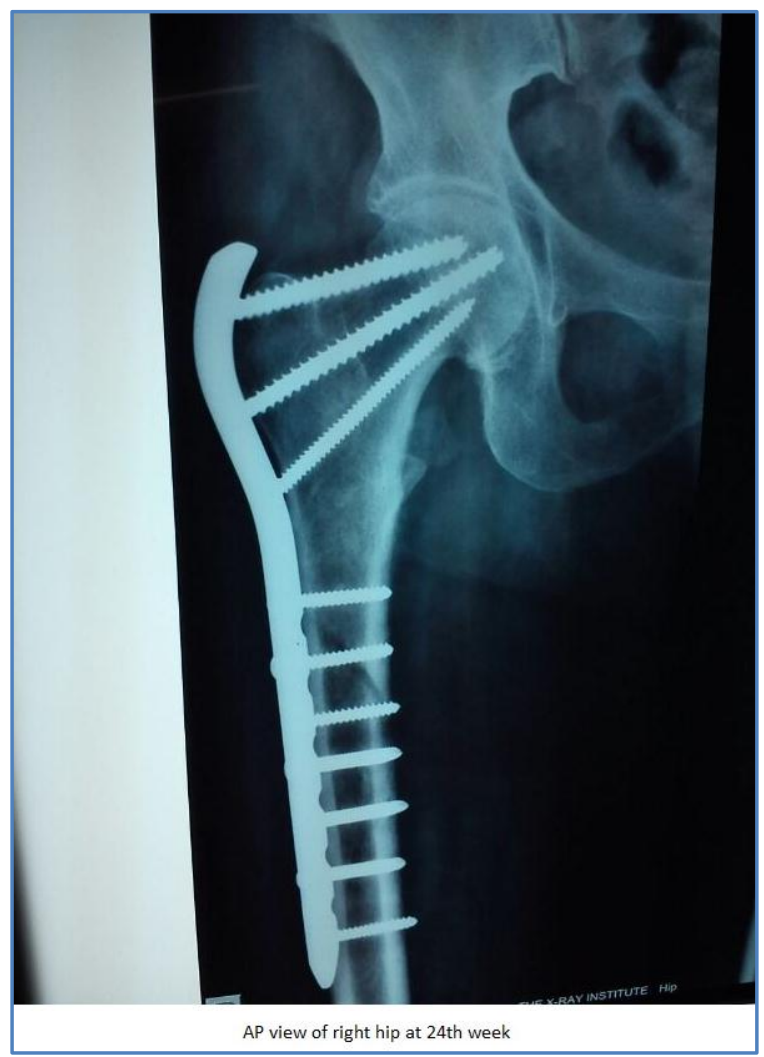

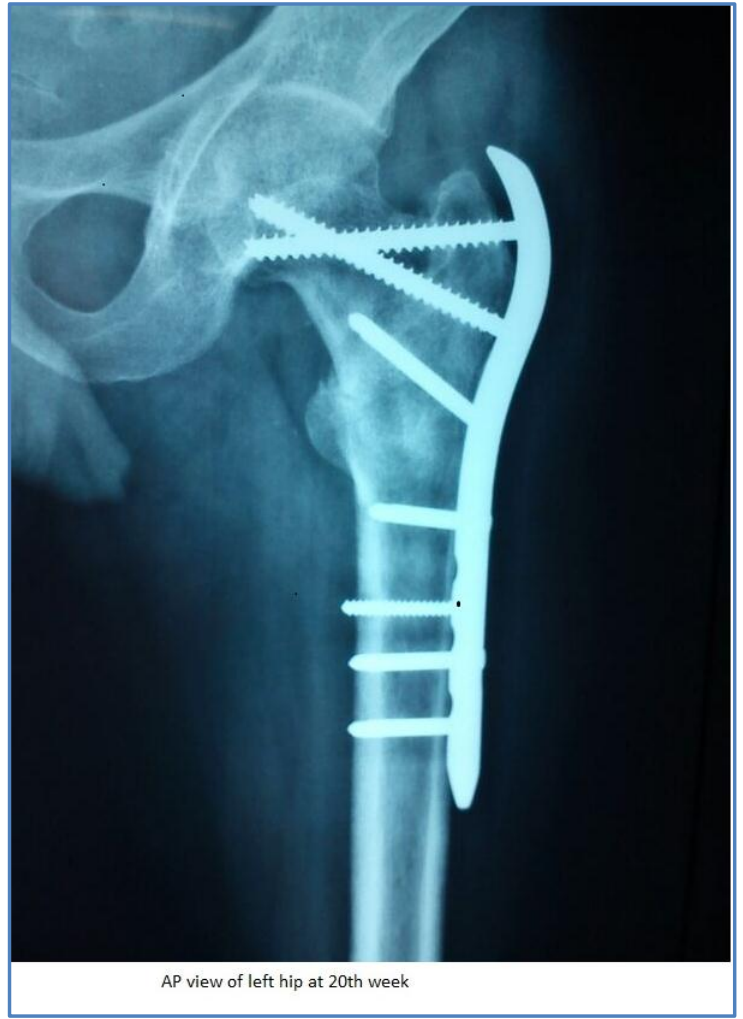

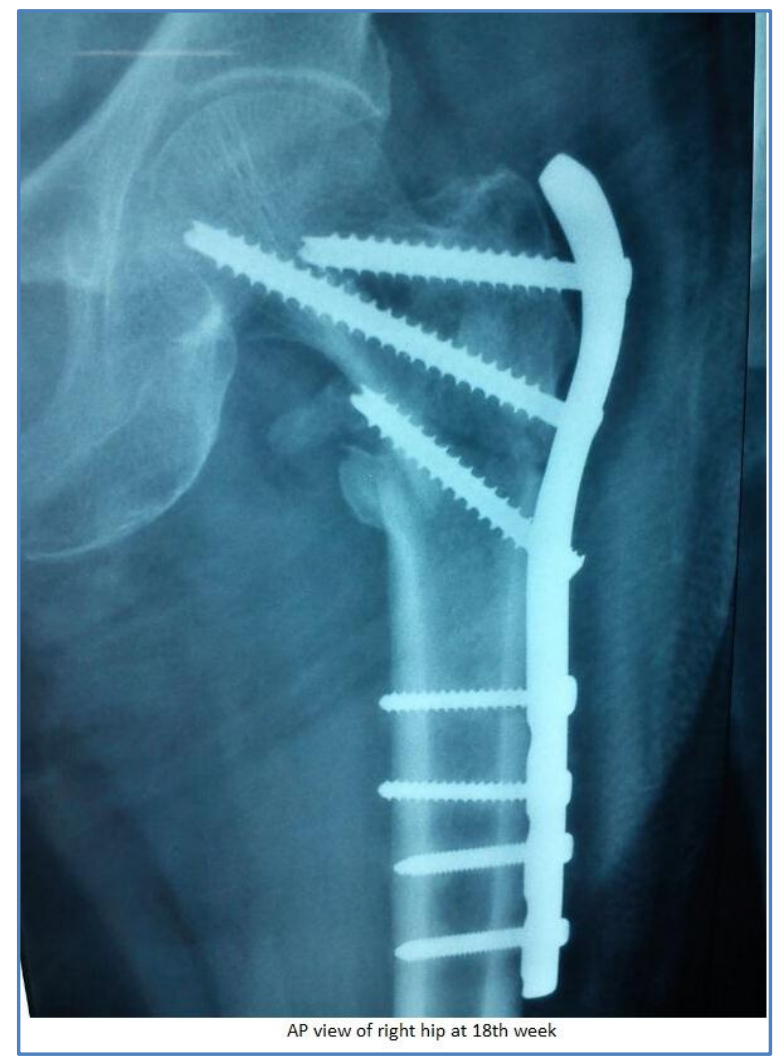




\section{ORIGINAL ARTICLE}
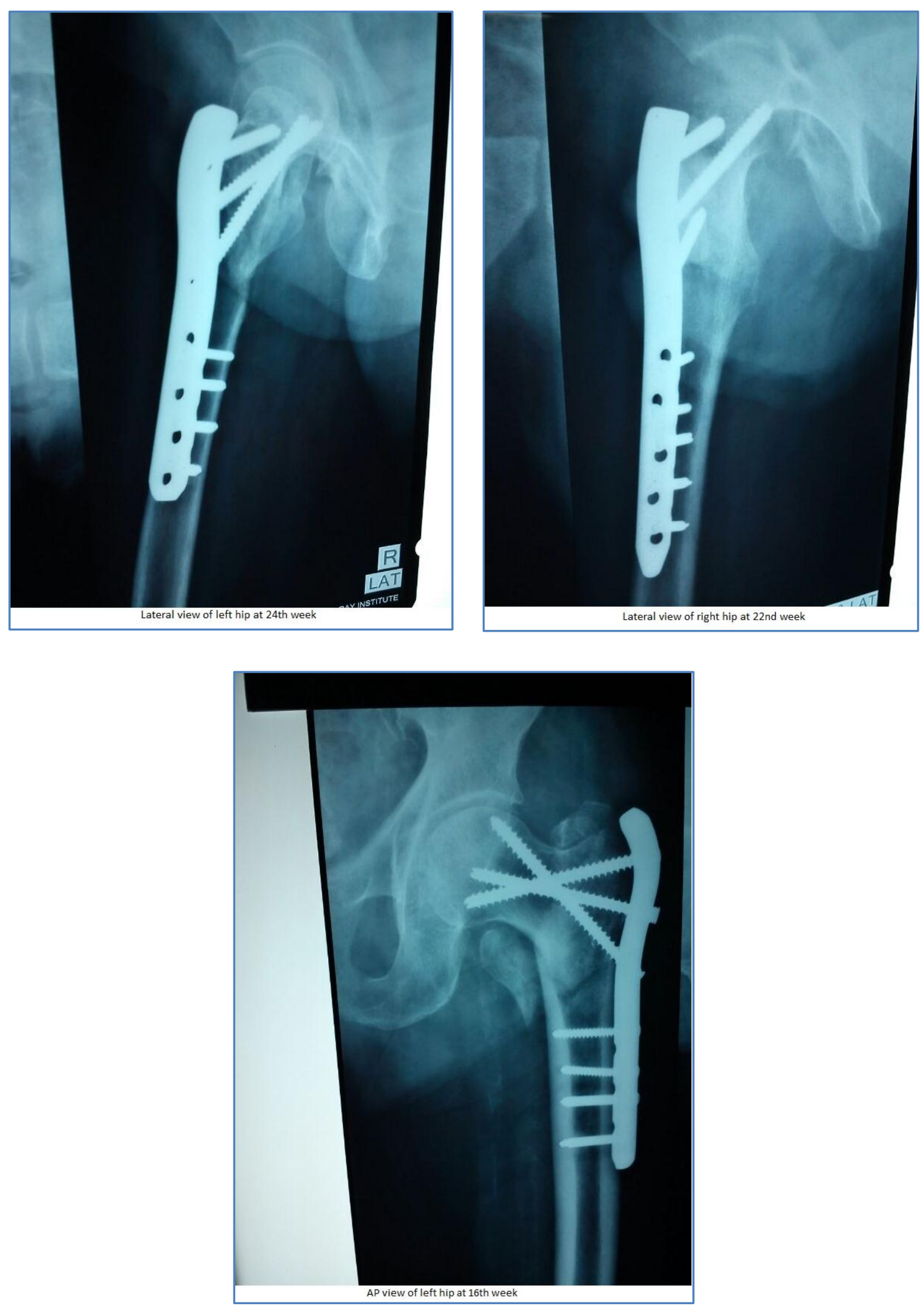


\section{ORIGINAL ARTICLE}

\section{AUTHORS:}

1. Kiran Kalaiah

2. H. P. Shobha

3. Giridhar Kumar

4. Vimalan G.

\section{PARTICULARS OF CONTRIBUTORS:}

1. Professor and HOD, Department of Orthopaedics, MMC \& RI, Mysore.

2. Assistant Professor, Department of Orthopaedics, MMC \& RI, Mysore.

3. Senior Resident, Department of Orthopaedics, MMC \& RI, Mysore.

4. Post Graduate Student, Department of Orthopaedics, MMC \& RT, Mysore.

\section{NAME ADDRESS EMAIL ID OF THE} CORRESPONDING AUTHOR:

Dr. H. P. Shobha,

Assistant Professor,

Department of Orthopaedics,

KR Hospital,

MMC \& RI,

Mysore.

Email: shobha.ortho@yahoo.com

Date of Submission: 04/07/2014.

Date of Peer Review: 05/07/2014.

Date of Acceptance: 09/07/2014.

Date of Publishing: 15/07/2014. 